\title{
A reforma do Ensino Médio: A nova formulacão curricular e a realidade da escola pública
}

\author{
José Juiz Domingues*, \\ Nirza Seabra Toschi* ${ }^{* *}$ \\ João Ferreira de Oliveira***
}

\begin{abstract}
RESUMO: O texto discute a nova formulação curricular do Ensino Médio e a realidade da escola pública com base em uma visão tripartite dessa política educacional: currículo, formação de professores e gestão. Analisa, sobretudo, o processo de diversificação e flexibilização na nova organização curricular e a formulação da estrutura curricular escolarizada, destacando os conceitos de interdisciplinaridade e de contextualização, bem como os acertos e desacertos da proposta curricular atual.
\end{abstract}

Palavras-chave: Ensino Médio, educação tecnológica, reforma do ensino técnico

Os autores do presente texto dedicam-se há vários anos ao estudo das políticas educacionais, com base em um enfoque tripartite que inclui a questão curricular, a formação de professores e a gestão da educação escolar. Esse enfoque integrado possibilita a visão de um mesmo objeto de estudo - a política educacional - de forma mais abrangente e totalizadora, numa perspectiva de avaliação crítica da mesma. Assim, a temática que se propõe discutir nessa sessão especial - acertos e de-

\footnotetext{
* Professor na Faculdade de Educação e pró-reitor de pesquisa e pós-graduação da Universidade Federal de Goiás (UFG). Email: domingues@netline.com.br

** Professora na Faculdade de Educação da UFG e doutoranda em Educação na Universidade Metodista de Piracicaba (Unimep). Email: ranzi@netpar.com.br

*** Professor na Faculdade de Educação da UFG e doutorando na Faculdade de Educação da USP.
} 
sacertos na proposta curricular para o Ensino Médio ${ }^{1}$ - será analisada com base nessa tríplice dimensão de estudo e análise.

No que se refere à dimensão curricular - ponto central da reforma consubstanciada no Parecer CEB/CNE n ${ }^{\circ}$ 154, de 25 de junho de 1998, e na Resolução CEB/CNE no 3 , de 26 de junho de 1998 -, salientamos que este estudo articula-se com dois outros textos apresentados por José Luiz Domingues em reunião da Anped, em 1997 e 1998, sobre o currículo no governo Fernando Henrique Cardoso. O primeiro abordava os Parâmetros Curriculares Nacionais (PCNs), deixando evidente que estes mantinham as mesmas características de reformas anteriores, trazendo o passado ao presente. O segundo texto tratou da política curricular pós-1995, enfatizando que a avaliação em curso remonta às mesmas práticas da década de 1970, particularmente vinculadas ao tecnicismo educacional.

Acreditamos que toda mudança curricular é parte de uma política de desenvolvimento do país, e, portanto, o currículo deve expressar coerência e articulação com esse projeto. Isso explica, em grande parte, porque o planejamento curricular está adquirindo centralidade nas reformas educativas, especialmente na América Latina. No caso brasileiro, isso se evidencia nas reformas curriculares em curso (PCNs do Ensino Fundamental e Médio e Diretrizes Curriculares Nacionais para a educação básica e superior) e nos mecanismos de avaliação do sistema (Saeb, Enem, ENC, Paiub etc.).

No Brasil, apesar da importância que os governos dão ao planejamento curricular, a história tem demonstrado que, sucessivamente, as reformas "fracassam". É o que demonstra a maioria dos estudos acerca, por exemplo, das reformas de 1960 (Lei no 4024/61) e 1970 (Lei no 5692/71). Por que elas fracassaram? Será que os mesmos equívocos se repetem na atual reforma do Ensino Médio? Naquelas, o insucesso se deveu, basicamente, à ausência de financiamento do processo de manutenção e investimento e à falta de uma política "agressiva" de formação de professores e de recursos humanos em geral. Deveu-se também à ausência de uma política de adequação do espaço e da infra-estrutura pedagógica, além da inexistência de uma política editorial que superasse o passado.

Em geral, essas políticas de currículo têm se caracterizado como programas de governo, isto é, com início e fim determinados pelos mandatos. Falta tempo para sua implantação e consolidação no espaço de um governo, acarretando descontinuidade administrativa e pedagógica. O mais grave é que tais políticas levam ao descrédito no âmbito escolar, uma vez que os professores não acreditam nelas, e, portanto, não se engajam efetivamente. 
Outro aspecto que deve ser ressaltado é que os movimentos reformistas de 1960 e 1970 tiveram financiamento externo no processo de elaboração. Nessas reformas, em geral, as equipes foram bem remuneradas e contaram com o apoio de assessores estrangeiros. Entretanto, o processo de implementação e manutenção das propostas não contou com verbas suplementares que garantissem a continuidade. O mesmo pode acontecer na atual reforma curricular do Ensino Médio.

A literatura sobre currículo tem demonstrado que geralmente as reformas não decorrem de necessidades nacionais coletivas. A transposição curricular estrangeira tem sido uma constante nessa área, apesar da existência de um pensamento curricular nacional emergente. Os professores têm sido tomados como recursos nas propostas e não como agentes, mesmo quando supostamente ouvidos no processo de elaboração. Daí o descompromisso social com a mudança.

Portanto, acreditamos que a investigação e a implementação dessa reforma do Ensino Médio devam ser consideradas com base nos parâmetros acima apresentados. Nessa fase da reforma, buscaremos analisar as proposições formuladas e consolidadas, basicamente, no Parecer CEB/CNE n $15 / 98$ e na Resolução CEB/CNE n $3 / 98$, sem a pretensão de esgotá-los.

Os principais componentes curriculares, presentes na atual reforma do Ensino Médio, serão discutidos com base em uma visão tripartite: currículo, formação de professores e gestão. O texto está estruturado em dois tópicos. O primeiro trata da diversificação e da flexibilização na organização curricular. O segundo discute a formulação da estrutura curricular escolarizada, destacando os conceitos de interdisciplinaridade e contextualização.

\section{Diversificação e flexíbilização curricular:}

\section{A formação básica e a preparação geral para o trabalho}

Desde o início das primeiras formulações, da Secretaria da Educação Média e Tecnológica do Ministério da Educação e do Desporto (Semtec/MEC), para a reforma do Ensino Médio, ${ }^{2}$ iniciadas no primeiro governo Fernando Henrique Cardoso (1994-1998), incluíram-se como diretrizes fundamentais:

a) a identificação do Ensino Médio com a formação geral básica, articulada com uma perspectiva de educação tecnológica e com o mundo do trabalho; 
b) o ideário de diversificação e flexibilização curricular, como forma de estabelecer um modelo educacional flexível de atendimento às diferentes clientelas;

c) a autonomia da escola e do aluno na adequação curricular, favorecendo o processo formativo contextualizado;

d) a definição de diretrizes curriculares nacionais que privilegiassem as competências e as habilidades básicas voltadas para o trânsito e a complementaridade entre o ensino regular e a formação profissional.

Nessas formulações, duas questões eram muito recorrentes. A primeira dizia respeito ao processo de autonomização da escola no âmbito da diversificação da organização curricular, de acordo com as características dos alunos e com as demandas de cada contexto social. A segunda referia-se à adequação curricular disciplinar dos sistemas de ensino e das escolas, em particular, a dois princípios pedagógicos compreendidos como eixos organizadores do novo currículo, ou seja, a interdisciplinaridade e a contextualização, mediante interação entre as diferentes áreas de conhecimento.

O Ensino Médio foi configurado na LDB (Lei n 9394/96) como a última etapa da educação básica. Esse fato novo se deu num momento em que a sociedade contemporânea vive profundas alterações de ordem tecnológica e econômico-financeira. O desenvolvimento científico e tecnológico das últimas décadas não só transformou a vida social, como causou profundas alterações no processo produtivo que se intelectualizou, tecnologizou, e passa a exigir um novo profissional, diferente do requerido pelos modelos taylorista e fordista de divisão social do trabalho. A sociedade contemporânea aponta para a exigência de uma educação diferenciada, uma vez que a tecnologia está impregnada nas diferentes esferas da vida social.

A idéia do Ensino Médio como parte da educação básica está em consonância com esse novo contexto educacional, uma vez que, segundo a LDB, objetiva consolidar e aprofundar os conhecimentos adquiridos na educação fundamental, desenvolver a compreensão e o domínio dos fundamentos científicos e tecnológicos que presidem a produção moderna, e não apenas preparar para o vestibular. Ocorre, porém, que a educação média tem sido, historicamente, seletiva e vulnerável à desigualdade social.

Apesar de a Constituição Federal de 1988, assim como a LDB, estabelecerem a progressiva extensão da obrigatoriedade e da gratuidade do Ensino Médio, 25\% dos adolescentes brasileiros entre 15 e 17 anos continuam sem estudar, e apenas $32,6 \%$ freqüentam escolas de Ensino 
Médio. No entanto, o número de matrículas nesse nível de ensino vem crescendo rapidamente. De 1994 a 1999 ocorreu um crescimento de $57,3 \%$, sendo que, no último ano, foi de $11,5 \%$. Tal crescimento é, em grande parte, decorrente da quase universalização do Ensino Fundamental, na faixa dos 7 a 14 anos, e da maior exigência de escolarização no recrutamento para os postos de trabalho. Esse aumento no número de matrículas tem ocorrido justamente na rede pública estadual e em cursos noturnos, o que evidencia que o Ensino Médio tem incorporado grupos sociais que se encontravam excluídos desse nível de ensino.

Além desse aspecto, há a "onda de adolescentes" (Parecer CEB/ CNE $n^{\circ}$ 15/98, p. 8), fenômeno que se refere a um progressivo aumento de jovens entre 15 e 18 anos. Como esse fenômeno demográfico está ocorrendo em época de escassez de ofertas de trabalho, boa parte desses jovens tenta permanecer mais tempo na escola, de forma a obter mais habilidades para competir com maiores oportunidades no mercado de trabalho. Isso nos remete à discussão sobre a função social da escola. Se há pouco emprego e o desemprego é estrutural, fica mais claro que a função da escola vai muito além da preparação ou da habilitação para o trabalho.

Retomando o contexto da sociedade tecnológica e o novo ambiente produtivo, vê-se que é exigida uma formação que inclui flexibilidade funcional, criatividade, autonomia de decisões, capacidade de trabalhar em equipe, capacidade de exercer múltiplos papéis e executar diferentes tarefas, autonomia intelectual, pensamento crítico, capacidade de solucionar problemas etc. O perfil e a formação cultural do candidato estão sendo amplamente valorizados nos processos de recrutamento para o mercado de trabalho. ${ }^{3}$ Deveria, então, a educação média subordinar-se às necessidades da economia, atender às carências do mercado de trabaIho? Subordinar-se a tais exigências estaria significando aceitar a competição capitalista e negligenciar o espírito cooperativo entre as pessoas?

Vitor Paro (1998, p. 6) alerta para o equívoco de se confundir trabalho como mediação e trabalho como fim, e assevera:

A centralidade do trabalho na sociedade está precisamente em seu poder de explicação dessa sociedade e da história, não podendo, entretanto, ser confundido com a razão de ser e objetivo último do homem enquanto ser histórico. $O$ trabalho possibilita essa historicidade, não é a razão de ser dela. $O$ trabalho é central porque possibilita a realização do bem viver, que é precisamente o usufruir de tudo que o trabalho pode propiciar. 
As tarefas da escola vão além das aspirações de preparar para o trabalho, embora ela contribua para essa tarefa. Se pretende formar para a cidadania, a educação média deve atualizar histórica, social e tecnologicamente os jovens cidadãos. Isso implica a preparação para o bem viver, dotando o aluno de um saber crítico sobre o trabalho alienado.

Como última etapa da educação básica, o Ensino Médio tem como finalidade consolidar e aprofundar os conhecimentos adquiridos no Ensino Fundamental, além de possibilitar o prosseguimento de estudos. No artigo 35 da LDB fica claro também que a finalidade do Ensino Médio é "a preparação para o trabalho e a cidadania do educando, para continuar aprendendo, de modo que seja capaz de se adaptar com flexibilidade a novas condições de ocupação ou aperfeiçoamento posteriores". Tais dispositivos legais deixam à mostra a própria condição desse grau de estudos de se relacionar com dois outros níveis de ensino. Ensino Médio é o que está no meio, entre o Fundamental e o Superior. Essa condição de estar no meio configura esse nível de ensino como despido de identidade própria, especialmente pelo caráter homogeneizador causado pelo vestibular, ou melhor, pelo processo seletivo para ingresso no Ensino Superior. Segundo a reforma, é preciso dar uma identidade ao Ensino Médio. Identidade que será construída com base em um conceito que entenda esse nível de ensino como aquele que contempla a formação geral sólida e a preparação básica para o trabalho.

A identidade do Ensino Médio, na atual reforma, será constituída pedagogicamente com base em um currículo diversificado e flexibilizado. Esse é considerado o grande eixo das mudanças no Ensino Médio. Socialmente, a identidade do Ensino Médio estará condicionada à incorporação das necessidades locais - características dos alunos e participação de professores e famílias na configuração do que é adequado a cada escola. O novo currículo envolve a base comum nacional e a parte diversificada, com conteúdos e habilidades a serem definidos clara e livremente pelos sistemas de ensino e pelas escolas, dentro dos princípios pedagógicos de identidade, diversidade e autonomia, como forma de adequação às necessidades dos alunos e ao meio social (art. $7^{\circ}$ ).

Vale lembrar, todavia, que o discurso da diversificação e da flexibilização não é novo, uma vez que está presente na Lei $n^{\circ}$ 4024/61 e na Lei $n^{\circ} 5692 / 71$. Nesses casos, a diversificação e a flexibilização perderam-se na trajetória, no processo de implementação das reformas. Acontece que, do nível nacional à unidade escolar, tem se chegado, quase sempre, a um currículo único. A perda ocorrida desnuda a falsidade desses 
princípios, uma vez que o currículo se torna único. Magendzo (1991) afirma que, se a diversificação e a flexibilização fossem verdadeiros princípios do planejamento curricular, este não seria centralizado como efetivamente o é. A descentralização, inclusive, pressupõe uma concepção diferente de professor. Este seria compreendido como agente do currículo, e não como transmissor de uma cultura selecionada por outros. Além disso, a normatização curricular dos conselhos de educação e os livros didáticos colaboram significativamente para a padronização curricular.

Como se observa no Parecer $n^{\circ} 15 / 98$, que acompanha a Resolução CEB/CNE nº 3/98, enquanto a LDB dá direções mais duradouras da educação nacional, as Diretrizes Curriculares Nacionais (DCNs), por estarem mais próximas da ação pedagógica, funcionam como indicações que possibilitam acordos de ações e requerem revisões freqüentes. $A$ concepção de currículo a que se filiam (parecer e resolução) não o entende como algo pronto e acabado, definido por especialistas, mas compreende a escola como produtora de currículo, com professores que definem o que, como ensinar e por que ensinar tal ou qual conteúdo. Essa é uma questão extremamente significativa do ponto de vista da teoria curricular, mas que, certamente, precisa levar em conta a realidade escolar brasileira e as relações que se dão no âmbito da escola, uma vez que parece existir um descompasso entre essa nova proposição curricular e a prática pedagógica escolar atual. Tal proposição, por não considerar a concretude da escola, corre o risco de não contribuir para as necessárias mudanças nas práticas pedagógicas (Paro 1999).

\section{A escola e a formulação da estrutura curricular: Interdisciplinaridade e contextualização}

As grades curriculares do Ensino Médio não-profissionalizante (o chamado colegial) ainda em vigor na maioria das escolas brasileiras são formadas por componentes curriculares estabelecidos pela Lei $n^{\circ} 5.692 /$ 71 e pela legislação complementar. O núcleo comum é formado pelas disciplinas Língua Portuguesa, Literatura, Língua Estrangeira Moderna, Matemática, Biologia, Química, Física, História e Geografia, que ocupam quase toda a carga horária geral do curso. Na parte diversificada incluise a preparação para o trabalho, que se apresenta como disciplina ou pode ser desenvolvida de forma integrada com todas as matérias do núcleo comum. 
Como decorrência dessa formulação, foram elaborados os chamados guias curriculares e os programas curriculares, na maior parte dos estados brasileiros. Esses documentos, em sua maioria, foram simplesmente ignorados pelas escolas, uma vez que os professores continuaram a se pautar pelos livros didáticos disponíveis no mercado. Além disso, não obtiveram êxito porque não foram amplamente divulgados ou porque os professores não tiveram acesso a eles. Outro aspecto desse insucesso foi a ausência de uma formulação participativa e de uma adequada preparação docente. Portanto, de modo geral, esse modelo de currículo, com um elenco prescritivo e conteudista de disciplinas (matérias e seus programas), tem se mostrado inadequado.

Ao que parece, na nova proposição curricular, nem as escolas, nem os professores recebem um currículo pronto. A idéia é que os professores desenvolvam seu próprio currículo. Isso será possível, considerando a concretude da escola pública brasileira? Parece correto, pedagogicamente, que os professores assumam parte da responsabilidade que isso representa, uma vez que são eles que conhecem a realidade da escola e possuem um saber advindo de sua formação e da prática pedagógica. Embora os professores tenham sido, histórica e freqüentemente, levados a reproduzir o que os "curriculistas" definiam, hoje há numerosas experiências que confirmam o potencial criativo e reflexivo dos professores; o que os caracteriza como "aptos" a iniciar uma reforma na definição dos currículos, isto é, aptos a serem os curriculistas.

Isso não significa, no entanto, que os sistemas estejam isentos da condução dessa política educacional. Não significa deixar que as coisas aconteçam irresponsavelmente, nem tampouco deixar as escolas e os professores sem a necessária assessoria técnica nas dimensões pedagógica, social e epistemológica.

A estrutura curricular para o Ensino Médio, a ser definida coletivamente, em cada unidade escolar, deve ser precedida pela elaboração de proposta político-pedagógica. Nesta, os agentes escolares devem levar em consideração as diversas dimensões da autonomia da escola: a pedagógica, a administrativa, a jurídica e a financeira. ${ }^{4}$

Todos esses aspectos devem se fazer acompanhar de relações democráticas e horizontais no interior da escola e da sala de aula. Como formar o indivíduo autônomo e democrático, partícipe da vida social, se a escola - como local privilegiado para essa formação - não oferece, nem vive as condições reais de vida social democrática e autônoma? 
Na nova formulação curricular, definida pelo MEC e pelo CNE, as propostas de currículos, a serem desenvolvidas pelas escolas, devem incluir competências básicas, conteúdos e formas de tratamento dos conteúdos coerentes com os princípios pedagógicos de identidade, diversidade e autonomia, ${ }^{5}$ e também os princípios de interdisciplinaridade e contextualização, adotados como estruturadores do currículo do Ensino Médio. A interdisciplinaridade, que abriga uma visão epistemológica do conhecimento, e a contextualização, que trata das formas de ensinar e aprender, devem permitir a integração das duas outras dimensões do currículo:

a) a base nacional comum e a parte diversificada, e

b) a formação geral e a preparação básica para o trabalho.

A base nacional comum dos currículos é organizada em áreas do conhecimento:

a) linguagens, códigos e suas tecnologias;

b) ciências da natureza, matemática e suas tecnologias;

c) ciências humanas e suas tecnologias.

A definição de áreas do conhecimento é uma inovação que precisa ser discutida e aprofundada. Não há estudos curriculares sobre essa questão. Torna-se necessário, então, que estudiosos de currículo e epistemologia atentem para essa questão.

A idéia reinante no novo currículo é a de que a base comum deve ter tratamento metodológico que assegure a interdisciplinaridade e a contextualização, enquanto a parte diversificada deverá ser organicamente integrada com a base nacional comum, por contextualização que pode ocorrer por enriquecimento, ampliação, diversificação, desdobramento, por seleção de habilidades e competências da base nacional comum e por outras formas de integração. Isso deve ocorrer de acordo com o planejamento pedagógico e curricular da escola. A idéia nessa formulação curricular é que a parte diversificada dê a identidade de cada escola, isto é, defina a vocação de cada escola, pela priorização de uma das três áreas do currículo da educação média.

O princípio da contextualização deve orientar a organização da parte diversificada do currículo, de forma a evitar a separação entre ela e a base nacional comum, uma vez que a LDB assegura que as unidades escolares podem adequar seus conteúdos curriculares de acordo com as características regionais, locais e da vida de seus alunos. Outro princípio que deve ser organizador da parte diversificada é o conceito de trabalho concreto, isto é, o que vai além do processo produtivo e se refere à garantia da historicidade cultural dos homens. 
Os autores entendem, porém, que o princípio fundante e articulador da parte diversificada deve ser o conceito de democracia. Democracia entendida como controle da autoridade, isto é, controle dos poderes de decisão e execução. Esse conceito é que poderia sustentar a reforma do Ensino Médio: currículo integrado, gestão da escola e formação de professores. A democracia definiria o currículo, permearia a gestão da escola e a formação de professores, uma vez que a compreensão curricular pressupõe o entendimento da gestão da escola, do currículo e da formação de professores em sua dimensão democrática.

Outro ponto que vale destacar é que a divisão da proposta curricular em duas partes, base nacional comum e parte diversificada, também não é algo novo. Já esteve presente nas leis de 1960 e 1970 . Na atual reforma, todavia, a parte diversificada não tem a intenção de terminalidade profissional. Continua a centralização na formação acadêmica/propedêutica, uma das históricas exigências da classe média.

Como fazer para que esse acadêmico/propedêutico não seja barateado para $o$ imenso contingente de jovens que estão buscando o Ensino Médio atualmente? Será que vamos repetir a dualidade escolar no Ensino Médio, auxiliada por uma educação profissional paralela?

A interdisciplinaridade e a contextualização, segundo a reforma, devem ser o recurso para conseguir superar o arbítrio da proposição de áreas, ou agrupamentos de conteúdos, adequando-as às características dos alunos e do ambiente socioeconômico. Assim, a interdisciplinaridade e a contextualização, segundo propõe a reforma, podem possibilitar a reorganização das experiências dos agentes da escola, de forma que revejam suas práticas, discutam sobre o que ensinam e como ensinam.

Apesar da força da disciplinaridade, a interdisciplinaridade está ganhando vigor extraordinário nas últimas décadas. ${ }^{6}$ Tem sido freqüente neste século a reorganização do conhecimento. Conforme analisa Santomé (1998), "a cultura, mentalidade e expectativas de qualquer pessoa são fruto de uma história vivida no seio de uma ou várias famílias, resultado de sua participação ativa dentro de grupos sociais étnicos, de gênero, de condicionantes geográficos, históricos, biológicos etc.". Se admitimos a diversidade de experiências na vida humana, a compreensão de qualquer fenômeno social deve levar em consideração essas dimensões, uma vez que a realidade é multidimensional. Assim, apostar na interdisciplinaridade, acreditar na possibilidade de integração das diferentes áreas de saber, agregando-as às diversidades culturais, "significa defender um novo tipo de pessoa, mais aberta, flexível, solidária, democrática e crítica” (p. 45). 
Forquin (1993) assinala que a oferta cultural escolar vive a tensão permanente entre a cultura escolar e a cultura da vida cotidiana. Pela função social da escola, que é a iniciação sistemática a instrumentos cognitivos essenciais da atividade humana, a escola não é inimiga da novidade, mas não partilha o gosto pelo efêmero e o culto das aparências. A escola contém ao mesmo tempo o mosteiro e a cidadela, quer dizer, preserva os saberes mais constantes, mais universais, mais incontestáveis da herança científica acumulada, que dificilmente seriam colocados em outros lugares que não o ambiente escolar, mas valoriza saberes adequados a seu tempo histórico, à sociedade informático-mediática (Levy 1993) em que vivemos, entendida, contudo, como resultante do desenvolvimento científico e tecnológico, que possui, por sua vez, um valor intelectual intrínseco, passível, portanto, de estar presente no currículo escolar.

Assim, fazendo a transposição para a reforma da educação média, pode-se dizer que a formação geral constitui os conhecimentos mais universais, o mosteiro, enquanto a preparação básica para o trabalho englobaria a historicidade do mundo contemporâneo, a cidadela.

A contextualização, na nova formulação curricular do Ensino Médio, deve permitir que o currículo se transforme num confronto de saberes, entre os conteúdos da base nacional comum e os da parte diversificada. Dessa forma, apesar da organicidade que caracteriza o currículo pleno (base nacional comum mais parte diversificada), a seleção da base nacional comum deve levar à compreensão do currículo como algo a ser construído. Por meio da contextualização seria possível relacionar disciplinas com o cotidiano dos alunos, com a realidade das escolas, com as características locais e regionais. Isso significa, em outras palavras, conseguir uma "sintonia fina" entre a interdisciplinaridade e a contextualização, revelando a identidade de cada escola, o que é expresso na sua autonomia pedagógica. É justamente a aprendizagem permanente dos agentes escolares no planejamento curricular, construído coletivamente, que pode meIhorar a ação educativa de cada escola de educação média.

Vale destacar a dificuldade que as escolas poderão ter com a falta de material didático que contemple as exigências da sociedade tecnológica, bem como a proposta de ensino a ela conveniente. Os atuais materiais didáticos, tais como livros didáticos com conteúdos selecionados pelas editoras e apostilas, foram concebidos, em geral, para modelarem o ensino a um formato curricular homogêneo, vinculado a um paradigma curricular que se liga à racionalidade técnica, do tipo preparação para concursos vestibulares. 
Ocorre, porém, que a interdisciplinaridade e a contextualização também não são coisas novas. O difícil é transformar isso em realidade, ou seja, em práticas escolares cotidianas. As dificuldades vão além da questão epistemológica e os obstáculos de ordem pessoal, institucional e de formação de professores adquirem relevância.

O Enem é um exemplo dessas dificuldades, mesmo no âmbito do próprio MEC. Embora haja a intenção explícita de "associar e relacionar conteúdos" (Avancini 1999, p. 4), ${ }^{7}$ as provas reeditam os paradigmas disciplinares e "padronizam a diversidade". ${ }^{8}$ Isso ocorre, em parte, porque as matrizes curriculares desse exame são disciplinares. Trabalha-se com competências e habilidades mensuráveis. Além disso, há o risco de que o Enem seja tomado como modelo curricular, a exemplo do que tem ocorrido com o vestibular/processo seletivo. Como garantir que, na seleção para o ingresso no Ensino Superior, seja contemplada a flexibilidade prevista na LDB, uma vez que essa avaliação nacional passa a ser apresentada como a alternativa complementar básica às provas do antigo vestibular? De que modo, portanto, o Enem se articula com a reforma curricular do Ensino Médio?

As três áreas designadas na Resolução CEB/CNE nº 03/98 vêm acompanhadas pelo termo tecnologias. Ao que parece, o objetivo é conectar os conhecimentos científicos a suas aplicações tecnológicas, identificando nas diversas ciências que compõem o currículo escolar os elementos de tecnologia que são essenciais a cada uma das áreas de conhecimento, desenvolvendo-os como conteúdos vivos, meios de educação (Parecer $n^{\circ}$ 15/ 98, p. 57). De fato, é fundamental generalizar o uso de multimeios interativos até mesmo nos cursos presenciais de educação média. É preciso integrar a informática, o uso da televisão, do vídeo, do rádio, na formação regular do Ensino Médio. É preciso equipar as escolas com recursos da informática e de multimídia, fax, telefone e reprodutor de textos.

Não basta, porém, levar tais mídias para a escola sem uma concomitante preparação dos recursos humanos, particularmente dos professores. Há de se preparar professores com tais competências em cursos de capacitação permanente, mas, especialmente, nos cursos de formação inicial de professores. É preciso criar uma dinâmica de aprimoramento permanente dos professores, não apenas em relação às mídias, mas sobretudo em relação às áreas específicas do conhecimento, como também no que se refere à avaliação da aprendizagem, possibilitandoIhes momentos para troca de experiências, de maneira que sejam difundidas, pelos próprios professores, as mais bem-sucedidas. Não se pode dar o que não se tem. Se os professores não dominam o manuseio e o 
funcionamento das tecnologias, como ensiná-los aos alunos? Além do mais, os jovens têm demonstrado maior facilidade com as tecnologias do que a maior parte de seus professores.

\section{Considerações finais}

A nova formulação curricular, proposta pela reforma do Ensino Médio, pode ser considerada o eixo central das alterações para esse nível de ensino. Tal adequação provoca duas modificações extremamente significativas na estrutura atual. Por um lado, propõe substituir a atual centralização sistêmica, em termos curriculares e de gestão escolar, pela autonomização da organização pedagógica e curricular da escola. Isso significa ampliar o "poder" da escola e dos professores nesse campo da prática pedagógica, procurando escolarizar as definições sobre a proposta pedagógica e sobre as definições curriculares. Por outro lado, procura "desorganizar" o trabalho escolar baseado no paradigma disciplinar, para substituí-lo por práticas que favoreçam a interdisciplinaridade e a contextualização curricular.

Três dimensões, como salientamos anteriormente, estão diretamente envolvidas nesse processo: currículo, formação de professores e gestão da educação. Na primeira dimensão, verifica-se que os princípios curriculares propostos (interdisciplinaridade e contextualização), bem como a divisão curricular proposta (base nacional comum e parte diversificada), não são novos na tradição de reformas curriculares no país. Outro aspecto problemático é a existência de uma cultura de transmissão dos conhecimentos, derivada da escola tradicional, em detrimento de uma formação que desenvolva a formação de atitudes, valores e competências mais amplas.

Na segunda dimensão, a questão da formação, e mesmo da falta de professores para o Ensino Médio, constitui um sério obstáculo na implementação dessa reforma curricular. Tal reforma não se faz acompanhar de uma política efetiva de formação de professores, que os capacite adequadamente para enfrentar os novos desafios. Essa situação é bastante temerária, uma vez que a maioria dos estados brasileiros não desenvolve programas e pouco investe na formação de professores para a educação básica, ${ }^{9}$ mesmo com a obrigatoriedade estabelecida pela legislação atual. O que se nota, pelo contrário, é um aligeiramento na formação, sua desvinculação da pesquisa e da valorização da escola como locus central de formação continuada, que é a proposta da TV Escola. 
Além disso, a nova formulação curricular certamente exigirá uma adequação das instituições formativas, um maior contingente de profissionais docentes, especialmente considerando a existência de uma parte diversificada. E também exigirá a adoção de uma formação que supere as práticas exclusivamente disciplinares das matrizes curriculares atuais, seja na escola, seja nas instituições formativas.

A terceira dimensão refere-se "à falta de uma fonte fixa de financiamento para viabilizar a expansão do Ensino Médio e a nova proposta", ${ }^{10}$ especialmente porque esse nível de ensino é de responsabilidade dos governos estaduais. Nesse sentido, deve-se considerar ainda que 0 atual modelo deve ocasionar um aumento das despesas de controle e gerenciamento, sobretudo em decorrência de sua maior flexibilidade no processo de gestão, adequação e melhoria do espaço escolar e da maior qualificação requerida dos professores. É preciso também considerar que os parâmetros atuais de gestão das escolas, marcados pelo autoritarismo e pela pouca flexibilidade, falta de cultura de avaliação e de experiência de trabalho em equipe, mostram-se como obstáculos consideráveis ao êxito da reforma pretendida.

Assim, a gestão democrática da escola torna-se fundamental nesse empreendimento curricular. $O$ entendimento do currículo como construção coletiva, que envolve não apenas o sistema, pressupõe alterações substantivas em relação ao que é hoje realizado nas escolas. A participação dos membros do conselho escolar, junto com a direção, coordenação pedagógica, professores e alunos, é que definirá a proposta curricular da escola, a qual é parte do projeto pedagógico da unidade. Isso significa que a unidade escolar deixa de ser simples executora de fórmulas curriculares para se tornar um locus de reflexão e de tomada de decisão nessa matéria. Ao que parece, isso não está assegurado na atual reforma do Ensino Médio.

Por outro lado, a formação e o desenvolvimento profissional dos professores são de fundamental importância para o sucesso de qualquer reformulação curricular. O êxito dessa nova formulação curricular está diretamente vinculado à formação dos professores, a condições de trabalho adequadas e prazerosas conjugadas a um salário digno, para permitir que o professor assuma menos aula, ${ }^{11}$ de maneira que possa se dedicar integralmente e com mais afinco a uma só escola.

Cabe aos gestores dessa formulação curricular considerar a realidade da escola pública, a fim de evitar que as possíveis inovações se tornem, apenas, mais uma experiência curricular e mais uma política educacional descoladas da prática escolar e, portanto, fadadas ao fracasso. 


\section{Notas}

1. Sessão Especial realizada na 22ạ Reunião Anual da Anped, de 26 a 30 de setembro de 1999, em Caxambu (MG).

2. Folha de S. Paulo, Cotidiano 3, de 16 de setembro de 1999.

3. A esse respeito, a Folha de S. Paulo, Folha Teen, de 13/9/99, publicou matéria intitulada "Pare de pensar no diploma", na qual realça o valor que o mercado de trabalho tem dado ao perfil e à formação cultural dos candidatos.

4. A autonomia pedagógica está ligada à identidade da escola, à sua função social. Refere-se às medidas essencialmente pedagógicas, como definir cursos, explicitar objetivos, organizar e selecionar currículo, introduzir metodologias inovadoras, estabelecer cronogramas, calendários e horários escolares. São funções que estabelecem critérios próprios de organização da escola, descentralizando-os, com vistas à melhoria da qualidade social e cidadã do ensino. A autonomia administrativa consiste nos aspectos de gestão da unidade escolar, de sua organização, que dá liberdade para a escola elaborar e gerir seus planos, programas e projetos. A autonomia jurídica refere-se às ações tomadas no âmbito de seu regimento nas dimensões administrativa, pedagógica e disciplinar, bem como às orientações quanto a matrícula, transferência, concessão de graus etc. A autonomia financeira abrange os aspectos de independência financeira, controle e previsão de contas, além da captação de recursos complementares.

5. Tais princípios estão detalhados no Parecer CEB/CNE n 15/98 e na Resolução CEB/CNE no 03/98, que o acompanha.

6. O vestibular da PUC/SP 99 inovou ao diminuir o número de questões analítico-expositivas, mas tornando-as bidisciplinares. A intenção é cobrar dos estudantes o conhecimento da integração das áreas. O Exame Nacional do Ensino Médio (Enem), que pode vir a substituir o vestibular, em 98 já aplicou questões que uniam duas disciplinas (Folha de $S$. Paulo. Fovest 99, 10/12/98).

7. Folha de S. Paulo. Especial A: Enem 99, de 24/8/1999.

8. Folha de S. Paulo. Especial A: Enem 99, 30/8/1999.

9. Folha de S. Paulo. Cotidiano 2, p. 4, de 20/9/ 1999.

10. Folha de S. Paulo. Cotidiano 3. p. 3, de 16/9/1999.

11. É comum nas redes estaduais professores que assumem 40, 50 ou 60 aulas semanais, para melhorar o salário geral. São os salários baixos que levam a essa distorção, uma vez que a carga excessiva sobrecarrega e estressa os professores, irnpossibilitando-os de participar mais assiduamente da vida das escolas em que atuam.

Recebido para publicação em março de 2000 


\section{The high school reform: The new curriculum formulating and the state school reality}

ABSTRACT: This text discuss about the new high school curriculum and the state school means to perform this proposal, using a tripartite point of view: curriculum, technical knowledge and management. The process of diversification and flexibility of curriculum organization is analyzed, showing the concepts of inter-disciplinary and context as well the benefits and the mistakes of the new curriculum proposal.

\section{Referências bibliográficas}

ALENCASTRO VEIGA, IIma Passos (org.). Escola fundamental, currículo e ensino. Campinas: Papirus, 1991.

AMULDENA, Célia. "Professores apontam limites do exame". Folha de $S$. Paulo. Especial A Enem 99, 30/10/99.

AVANCINI, Marta. "Risco é Enem virar modelo curricular". Folha de $S$. Paulo. Especial A Enem 99, 24/08/99. . "Prova exige associação de conteúdos". Folha de S. Paulo. Especial A: Enem 99, 24/8/99.

BRASIL/CNE/CEB. Resolução CEB nº 03 de 26/06/98. Institui as DCN para o Ensino Médio.

BRASIL/CNE/CEB. Parecer no 5 de 0 1/06/98. DCN para o Ensino Médio. Relatora: Guiomar Namo de Mello.

BRASIL/MEC. LEI nº 9394, de 20/12/96. Lei de Diretrizes e Bases da Educação Nacional.

BRASIL/MEC/INEP. Plano Nacional de Educação. Proposta do Executivo ao Congresso Nacional. Brasília: MEC/Inep, 1998.

BRASIL/MEC/INEP. Censo Escolar. Anos 1997 e 1998.

BRASIL/MEC/SEMTEC. Área de ensino Sociedade e Cultura: Competências e habilidades específicas. Brasília, 1997. (Coord. Heloísa Dupas Penteado)

Área de ensino Códigos e Linguagens: Competências e habilidades específicas. Brasília, 1997. (Coord. Zuleide de Felice Murrie) 
CADERNOS de Educação. Educação Profissional. Brasília, CNTE, ano 1, $\mathrm{n}^{\circ}$ 1, jul./96. Decreto $\mathrm{n}^{\circ} 2208$ de 17/4/97, art. 5을 parágrafo único.

ESTADO DE GOIÁS. Proposta Curricular para o Ensino Médio da Secretaria de Educação e Cultura do Estado de Goiás. SUPEFM, 1995. Disciplinas: Matemática, Educação Física, Língua Portuguesa, Geografia, História, Química, Física, Biologia, Ensino Religioso.

FALCÃO, Daniela. "Matrícula do Ensino Médio cresce 11,5\%". Folha de S. Paulo. Cotidiano 3, 16/10/99, p. 3.

FLORESTA, Cleide. "Reforma depende de financiamento". Folha de $S$. Paulo. Cotidiano 3, 16/10/99, p. 3.

. "Sete estados investem na formação de professores". Folha de S. Paulo. Cotidiano 2, 20/10/99, p. 4.

FOLHA DE S. PAULO. Fuvest 99. 10/12/98.

. "Pare de pensar no diploma". Folhateen 13/9/99.

"Falta de professor será principal desafio". Cotidiano 3. Sucursal de Brasília, 16/10/99, p. 3.

FORQUIN, Jean-Claude. Escola e cultura: As bases sociais e epistemológicas do conhecimento escolar. Porto Alegre: Artes Médicas, 1993.

LEVY, Pierre. As tecnologias da inteligência: O futuro do pensamento na era da informática. Trad. de Carlos Irineu da Costa. São Paulo: Ed. 34, 1993.

PARO, Vitor Henrique. "Parem de preparar para o trabalho!!! Reflexões acerca dos efeitos do neoliberalismo sobre a gestão escolar e sobre o papel da escola básica". São Paulo: USP, 1998. (Mimeo.)

"Políticas educacionais: Considerações sobre o discurso genérico e a abstração da realidade". São Paulo: USP, 1999, 13p. (Mimeo.)

REVISTA do Ensino Médio.

SANTOMÉ, Jurjo Torres. Globalização e interdisciplinaridade: O currículo integrado. Porto Alegre: Artes Médicas, 1998.

SAVIANI, Dermeval. A nova lei da educação: Trajetória, limites e perspectivas. Campinas: Autores Associados, 1997.

Da nova $L D B$ ao novo Plano Nacional de Educação: Por uma outra política educacional. Campinas: Autores Associados, 1998.

SILVA, Luiz Heron da e outros (orgs.). Reestruturação curricular: Novos modelos culturais, novas perspectivas educacionais. Porto Alegre: Sulina, 1996. 